\title{
Unusual Idiopathic Calcinosis Cutis Universalis in a Child
}

\author{
Derya Alabaz ${ }^{a}$ Neslihan Mungan ${ }^{b} \quad$ Mehmet Turgut $^{c}$ \\ Cemil Dalay $^{d}$
}

Departments of aPediatric Infectious Diseases, bediatric Endocrinology, cPediatrics, and dPlastic Surgery, Çukurova University Faculty of Medicine, Balcalı, Turkey

\section{Key Words}

Calcinosis cutis · Idiopathic $\cdot$ Child $\cdot$ Pamidronate $\cdot$ Surgery

\begin{abstract}
Calcinosis cutis is an uncommon disorder characterized by the progressive deposition of crystals of calcium phosphate (hydroxyapatite) in the skin in various areas of the body. It is classified into four types according to etiology, namely as dystrophic if calcium and phosphorus levels are normal and tissue damage is present, as idiopathic if calcium and phosphorus levels are normal and no tissue damage is present, or as metastatic if there is hypercalcemia or hyperphosphatemia. Medical and surgical treatments are options to cure calcinosis cutis. Medical therapy is not very effective. Surgical excision has shown to be beneficial, as it can provide a symptomatic relief. However, since calcinosis cutis limits are not always well defined, a recurrence of the lesions may occur. We dealt with a very rare form of calcinosis cutis in a healthy 6-year-old girl. There was no evidence of connective tissue disorder or abnormal mineral metabolism. Hence, she was diagnosed as idiopathic calcinosis cutis and, although calcifications in idiopathic cutis are most commonly localized to one area, our patient unusually exhibited widespread calcific deposits. Although the existing lesions showed slow improvement, systemic pamidronate therapy was effective in preventing the occurrence of new lesions. Surgical excision proved to be an effective and successful treatment. This report aims to raise doctors' awareness on the presentation, etiopathogenesis, and course of the relatively rare idiopathic calcinosis cutis.
\end{abstract}

\section{Introduction}

Calcinosis cutis is an uncommon disorder which results in progressive deposition of insoluble calcium salts (crystals of calcium phosphate, hydroxyapatite) in the skin. Calcium deposits may be intracutaneous, subcutaneous, fascial and intramuscular, and sometimes involve visceral organs [1]. The course can be identified in most of the 


\begin{tabular}{l|l|l|l} 
Case Reports $h$ & Case Rep Dermatol 2009;1:16-22 & Published online: August 28, 2009 & $\begin{array}{l}\text { @ 2009 S. Karger AG, Basel } \\
\text { ISSN 1662-6567 } \\
\text { Wwww.karger.com/cde }\end{array}$ \\
\hline
\end{tabular}

circumstances by clinical evaluation and investigations. But in some cases, the etiology cannot be found out even after extensive work-up. Work-up in a patient diagnosed with calcinosis cutis includes a careful history of possible trauma or repetitive exposure to calcium salts. The history and physical examination should also elicit any sign or symptom of possible collagen vascular disorders. $\mathrm{X}$ ray examination or sonography of the extremities and trunk for dense shadows due to calcium is important. Biopsy plays an important role.

We herein report a child with calcinosis cutis who unusually exhibited widespread calcific deposits with an idiopathic etiology.

\section{Case Report}

A 6-year-old female child presented to our center complaining of multiple subcutaneous nodules that had progressed to pustules and ulcers with purulent discharge, which had started about 2 years ago on her hip and subsequently spread progressively to her arms, elbows and knees. Her past medical history revealed an operation in another center because of tendonitis (histopathologic diagnosis) in both knees at age $21 / 2$ years. There was no more information. There was no family history of similar lesions. At the time of presentation, the patient was otherwise healthy and had no complaints of joint pain, muscle weakness, skin rashes, Raynaud's phenomenon, dysphagia or dyspnea. She was not on any medication and had no known drug allergies.

On physical examination, we found numerous firm yellowish-white subcutaneous nodules approximately 3-7 cm in diameter on her trunk, arms, elbows, knees and legs bilaterally (fig. 1). Some of these lesions were soft and fluctuant and had a sinus overdischarging chalky white material of 2 years duration, while some comprised scar tissue. The systemic evaluation including the neurological examination were normal, and the patient had no symptoms such as muscle weakness or stiffness.

The laboratory investigations revealed within normal serum calcium $(10 \mathrm{mg} / \mathrm{dl}$, normal: $8.5-10.3$ $\mathrm{mg} / \mathrm{dl}$ ), phosphorus (4.9 mg/dl, normal: $3.0-6.0 \mathrm{mg} / \mathrm{dl}$ ) as well as serum 25 -hydroxy vitamin D (54 $\mathrm{ng} / \mathrm{dl}$, normal: $17-54 \mathrm{ng} / \mathrm{dl})$, parathormone $(\mathrm{PTH})(25 \mathrm{pg} / \mathrm{dl}$, normal: $11-54 \mathrm{pg} / \mathrm{dl})$ and osteocalcine (10 $\mathrm{mg} / \mathrm{dl}$, normal: $8.5-10.3 \mathrm{mg} / \mathrm{dl}$ ) levels done on different occasions. Biochemical examinations gave normal results for complete hemogram, erythrocyte sedimentation rate, blood sugar, uric acid, electrolyte, liver function and kidney function tests. Routine urine examination was normal. 24-hour urinary calcium ( $10 \mathrm{mg} / \mathrm{dl}$, normal: $8.5-10.3 \mathrm{mg} / \mathrm{dl})$ and phosphorus ( $0.36 \mathrm{~g}$, normal: $0.4-1.3 \mathrm{~g} / \mathrm{day})$ excretion were normal.

Screening tests for collagen vascular disease, including ANA, anti-DNA, anti-SM, ANCA, rheumatoid arthritis (RA) test, serum C3, C4 and CH50 levels were within normal limits. Tuberculin skin test was negative. Staphylococcus aureus was grown in bacteriological cultures of the purulent discharge.

Radiological examination showed that there was no bone pathology and no joint involvement, but widespread extensive amorphous calcifications in the soft tissues around joints. Ultrasonography showed that the calcifications were located in fat tissue under the skin, but not in deeper tissues or muscles. Investigations showed no indications of internal malignancy. Whole body tomography and bone marrow aspiration was normal.

Scintigraphic research showed no pathology in the thyroid and parathyroid. Hematoxylin- and eosin-strained histologic sections from excisional biopsies of lesions demonstrated deep cutaneous and/or subcutaneous deposits of homogenous material suggestive of calcium deposition, consistent with calcinosis cutis. On the basis of clinical, radiological and histopathologic data, a diagnosis of idiopathic calcinosis cutis universalis was made.

At the time of presentation, systemic therapy, such as cyclic intravenous pamidronate disodium (Aredia), was administrated every 2 months, $1 \mathrm{mg} / \mathrm{kg} /$ day for 3 days. In the follow-up time, some nodules became ulcerated and were complicated by repeated bacterial infections; some nodules required large surgical excisions and the dense chalk-like materials were removed successfully from the deposits in the hip and elbows without recurrence. Although the patient showed good tolerance, 2 years ago, 4year follow-up revealed minimal changes in the current lesions with this treatment. Consequently, pamidronate disodium was discontinued and the girl was started on prednisolone. Despite a trial of 3 


\begin{tabular}{l|l|l|l} 
Case Reports $h$ & $\begin{array}{l}\text { Case Rep Dermatol 2009;1:16-22 } \\
\text { D01: } 10.1159 / 000227285\end{array}$ & & $\begin{array}{l}\text { Published online: August 28, 2009 S. Karger AG, Basel } \\
\text { ISSN 1662-6567 } \\
\text { www.karger.com/cde }\end{array}$ \\
\hline
\end{tabular}

months with oral prednisolone ( $1 \mathrm{mg} / \mathrm{kg} /$ day) her condition began to deteriorate. She developed new lesions in the skin on multiple parts of the body (fig. 2), and abdominal hardness was noticed. Disclosed $\mathrm{X}$ ray and tomography of the abdomen showed that calcifications were located in the fat and muscle tissue under the skin, which were more evident at the right side, but not in deeper tissues. So, oral prednisolone was discontinued and intravenous pamidronate disodium was started in the same dose. Surgical excision of 3 selected fluctuant, subcutaneous nodules was performed due to severe pain and impaired mobility associated with the calcification. Recurrence did not occur. On 1-year follow-up, the current lesions had become smaller and no new lesions had appeared. After follow-up examinations over the last 2 years, the patient is still on intravenous pamidronate disodium. No new lesions have appeared and most of the old lesions have ulcerated and cicatrized (fig. 3 ).

\section{Discussion}

Calcinosis cutis has been described rarely in children [2]. It is due to a variety of etiologies and classically, it can be classified as metastatic, dystrophic and idiopathic types [3]. The pathogenesis of this condition is unknown and probably multifactorial. In metastatic calcinosis cutis, spontaneous deposition of calcium and phosphate in normal tissues is present due to increased serum calcium and/or phosphate levels or both. Calcium treatment, primary hyperparathyroidism, hypervitaminosis D, renal failure, milk-alkali syndrome, destructive bone disease, sarcoidosis and paraneoplastic hypercalcemia are some of the factors involved in increased serum calcium levels [4]. Dystrophic calcinosis cutis is the most common form and it may provide a history of an underlying disease associated with normal serum calcium and phosphate levels. Connective tissue disorders (including juvenile dermatomyositis, systemic lupus erythematosus, and systemic scleroderma), infections and local tissue traumas can be encountered in such primary pathologies $[5,6]$.

Idiopathic calcinosis cutis is a rare form and occurs in apparently normal tissue in the absence of known tissue injury, systemic metabolic effect or collagen vascular disease and percutaneous exposure to calcium [7]. The ultrastructural morphology of localized skin calcifications without associated diseases and with normal serum calcium and phosphate ion values is not entirely understood. Calcium and phosphate excretion may be low. Our patient was not considered to have metastatic calcification because the investigations of biochemical and radiological findings ruled out indications of any primary systemic disease. Moreover, serum calcium and phosphate levels were within normal limits. There was no evidence of primary skin injury, infection or connective tissue disorder known to cause dystrophic calcification, and screening tests for collagen vascular disease were negative. No causative factor is identifiable and, thus, the diagnosis of idiopathic calcinosis cutis was made in our case. Although calcification in idiopathic cutis is most commonly localized to one area, our patient unusually exhibited widespread calcified deposits. In recent reports, it was suggested that idiopathic calcinosis cutis lesions may be early findings of connective tissue disorders. Wananukul et al. [8] reported two cases of calcinosis cutis with onset years before other clinical manifestations of juvenile dermatomyositis were diagnosed. We suggested that the beginning of calcinosis started at age $21 / 2$, with tendonitis, so our patient had a long history of calcinosis. She may be an extensive calcinosis cutis case with onset years before other clinical manifestations of a systemic connective tissue disorder, but, so far, during the long follow-up time, there has been no evidence of another disorder.

A variety of drugs, including bisphosphonates, intralesional corticosteroids, aluminum hydroxide, warfarin, and diltiazem, and low calcium diet have been tried with less-thanideal success $[9,10]$. In idiopathic calcinosis cutis, surgical excision is an effective treatment and provides an accurate diagnosis [11], but can be considered as a last resort. 
However, excision or drainage should be limited to very carefully selected sites where pain and disability outweigh the risk of recurrence and further calcification due to surgical trauma. Spontaneous resolution of lesions has also been reported in cases of idiopathic calcinosis cutis in the scrotum and mons pubis. Our case is another observation which reports a noteworthy outcome of cutaneous lesions subsequent to treatment with pamidronate disodium (a nitrogen containing bisphosphonate), and surgery. We can consider pamidronate treatment successful because, although the clinical examination of the lesions revealed very slow regression in agreement with the literature, no new lesions occurred during therapy and severe progression of new lesions were noticed after cessation of pamidronate. In contrast to their use in osteopathy and hypercalcemia, there have been few reports on the use of bisphosphonates in conditions associated with calcinosis in pediatric practice, such as dermatomyositis, fibrodysplasia ossificans progressiva and scleroderma, and where they induced a favorable outcome. One report of a 6-year-old child with extensive subcutaneous calcification secondary to juvenile dermatomyositis documents the successful response of oral use of a bisphosphonate such as alendronate [12].

The primary bisphosphonate mechanism of action was the inhibition of osteoclastic bone resorption and the decrease in bone resorption [13, 14]. Some previous reports regarding the use of bisphosphonates in the treatment of ectopic calcifications also showed an anti-inflammatory effect and a significant reduction in the size of calcifications $[15,16]$. Bisphosphonates are known to have a strong effect on macrophage cell lineage, causing selective destruction of macrophages and inhibiting macrophage proinflammatory cytokine production (IL- $1 \beta$, IL-6, TNF- $\alpha$ ) and growth. The effect of bisphosphonates on macrophages may explain the reduction of inflammation in the calcified areas. Long-term treatment with pamidronate has resulted in increased calcium balance, catch-up linear growth before puberty, and no mineralization defects on bone biopsy. However, bone turnover is suppressed during therapy, and the impact of this in young infants and children is not known. However, our patient, who received pamidronate for more than 6 years, reportedly had normal growth and development, calcium serum concentrations, and urinary excretion at follow-up visits [14].

Excisions were performed carefully in 3 selected fluctuant, subcutaneous nodules due to severe pain and impaired mobility in these places in our patient. Recurrence did not occur. Perhaps the bisphosphonate therapy may have some role in this. Currently, the patient is undergoing systemic pamidronate treatment and is still under our observation.

In summary, we highlight the importance of identification of this rare but innocent disease and the use of bisphosphonates and surgical procedures in suitable patients without recurrence. A better understanding of the processes of calcinosis cutis by new case reports will lead to therapies which help to retard or improve this phenomenon and will probably have an important impact on patient morbidity. 
Fig. 1. Photograph showing the multiple firm erythematous-whitish nodules at the hips, arms and knees.

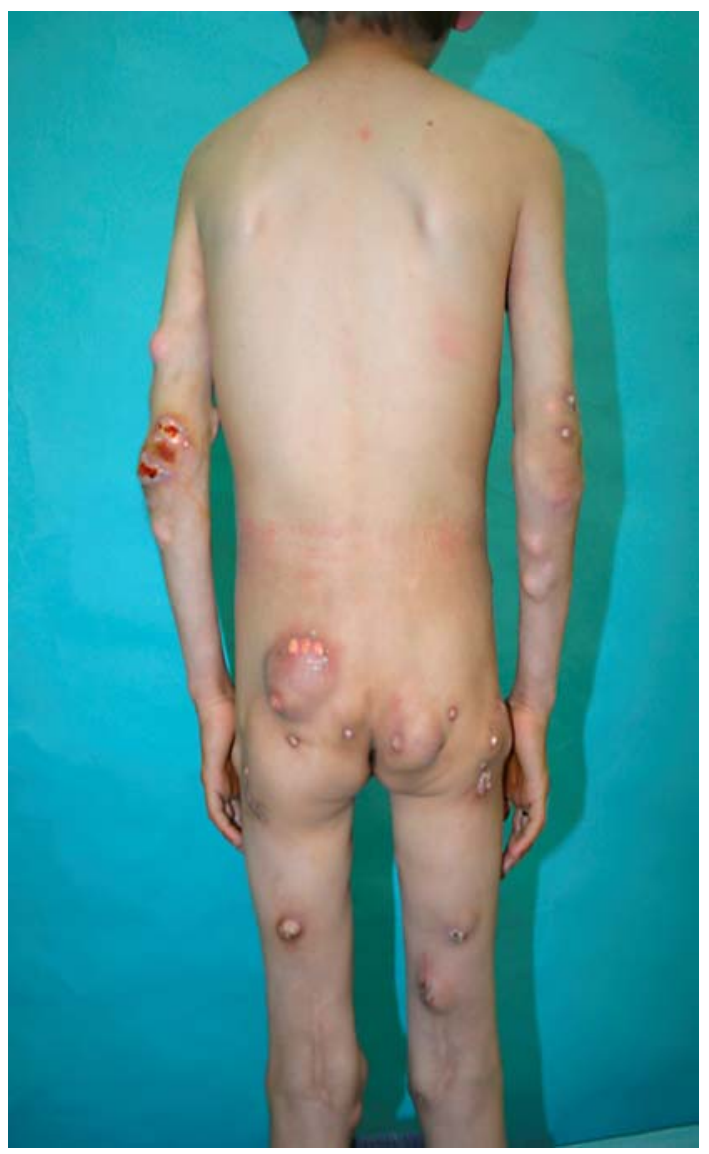


Fig. 2. Photograph of patient's hips, elbows and knees demonstrating multiple subcutaneous nodules 3 months after prednisolone start.

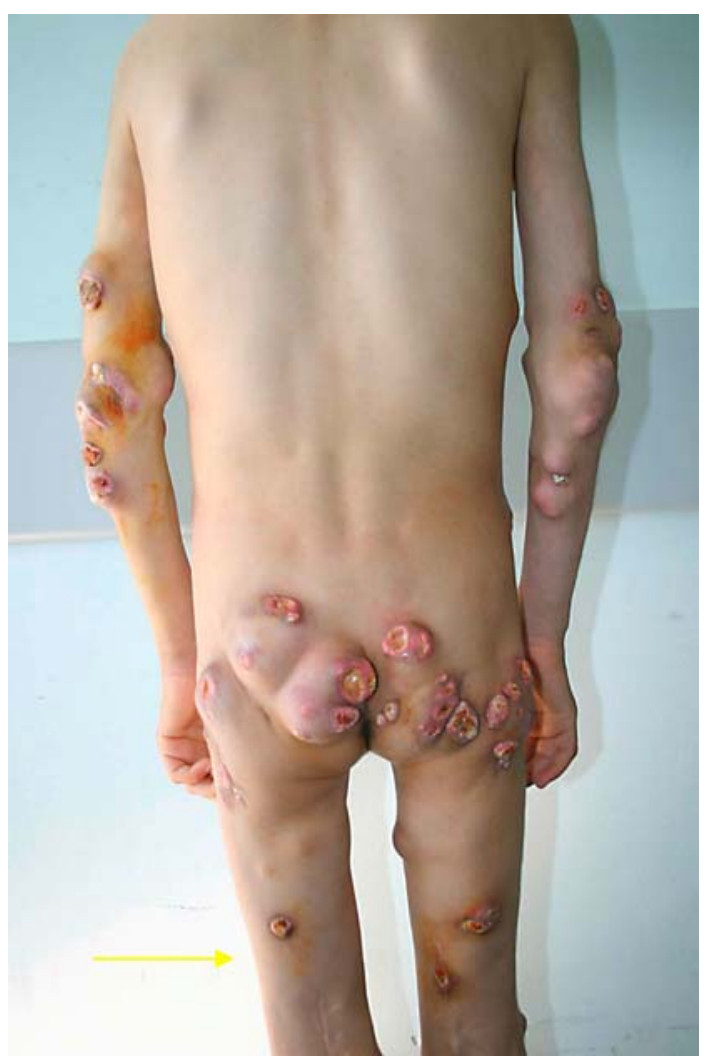

Fig. 3. Marked regression of the lesions in the hips (a), elbows (b) and knees (c) after 6 years of follow-up.

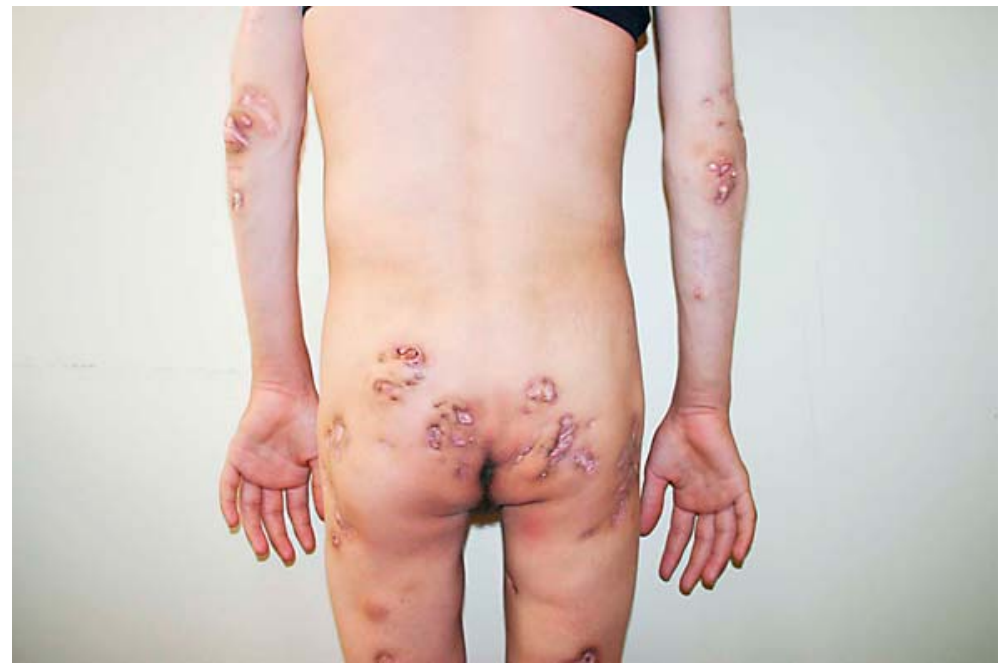




\section{References}

1 Walsh JS, Fairley JA: Calcifying disorders of the skin. J Am Acad Dermatol 1995;33:693-706.

2 Rodriguez-Cano L, Garcia-Patos V, Creus M, et al: Childhood calcinosis cutis. Pediatr Dermatol 1996;13:114-117.

-3 Puvabanditsin S, Garrow E, Titapiwatanakun R, Getachew R, Patel JB: Severe calcinosis cutis in an infant. Pediatr Radiol 2005;35:539-542.

-4 Zouboulis CC, Blume-Peytaui U, Lennert T: Fulminant metastatic calcinosis with cutaneous necrosis in a child with end-stage renal disease and tertiary hyperparathyroidism. Br J Dermatol 1996;135:617-622.

5 Lobo IM, Machado S, Teixeira M, Selores M: Calcinosis cutis: a rare feature of adult dermatomyositis. Dermatol Online J 2008;14:10.

-6 Tristano AG, Villarroel JL, Rodríguez MA, Millan A: Calcinosis cutis universalis in a patient with systemic lupus erythematosus. Clin Rheumatol 2006;25:70-74.

7 Guermazi A, Grigoryan M, Cordoliani F, Kérob D: Unusually diffuse idiopathic calcinosis cutis. Clin Rheumatol 2007;26:268-270.

8 Wananukul S, Pongprasit P, Wattanakrai P: Calcinosis cutis presenting years before other clinical manifestations of juvenile dermatomyositis: report of two cases. Australas J Dermatol 1997;38:202-205.

-9 Rodan GA: Mechanisms of action of bisphosphonates. Annu Rev Pharmacol Toxicol 1998;38:375-388.

10 Prica PA, Omid N, Than TN, Williamson MK: The amino bisphosphonate ibandronate prevents calciphylaxis in the rat at doses that inhibit bone resorption. Calcif Tissue Int 2002;71:356-363.

11 Dubois LA, Gray DK, Tweedie EJ: Surgical images: soft tissue. Calcinosis cutis. Can J Surg 2007;50:217-218.

-12 Mukamel M, Horev G, Mimouni M: New insight into calcinosis of juvenile dermatomyositis: a study of composition and treatment. J Pediatr 2001;138:763766.

13 Rodan GA: Mechanisms of action of bisphosphonates. Annu Rev Pharmcol Toxicol 1998;38:375-388.

14 Russell RG: Bisphosphonates: mode of action and pharmacology. Pediatrics 2007;119(suppl 2):S150-S162.

15 Monteforte P, Rovetta G: Change in size of periarthritis calcifications in patients with painful shoulder treated with injectable disodium-clodronate. Int J Clin Pharmacol Res 2002;22:7-12.

16 Phanish MK, Kallarackal G, Ravanan R, Lawson TM, Baboolal K: Tumoral calcinosis associated with pyrexia and systemic inflammatory response in a haemodialysis patient: successful treatment using intravenous pamidronate. Nephrol Dial Transplant 2000;15:1691-1693. 